\title{
Analisis Faktor Sosial Ekonomi Yang Mempengaruhi Curahan Jam Kerja Wanita Tani Padi Sawah Di Desa Haekto Kabupaten Timor Tengah Utara
}

\author{
Maria F Selan ${ }^{\mathrm{a}}$, Adeline Norawati Hutapea ${ }^{\mathrm{b}}$ \\ ${ }^{a}$ Fakultas Pertanian, Universitas Timor, Kefamenanu, TTU - NTT, Indonesia.Email : mariafitrianaselan66@gmail.com \\ ${ }^{b}$ Fakultas Pertanian, Universitas Timor, Kefamenanu, TTU - NTT, Indonesia.Email: adelinenorawati@gmail.com
}

\section{Article Info}

\section{Article history:}

Received 17 Agustus 2019

Received in revised form 29 Agustus 2019

Accepted 19 Oktober 2019

DOI:

https://doi.org/10.32938/ag.v4i4.551

Keywords:

Usahatani

Curahan Tenaga Kerja

Wanita Tani

\section{Pendahuluan}

Di Indonesia dewasa ini, umumnya orang menganggap bahwa tugas wanita sebagai Ibu rumah tangga adalah memelihara dan mengurus rumah tangga dengan sebaik-baiknya. Namun kenyataannya sekarang ini kaum Ibu dirumah tidak pernah tinggal diam dan selalu aktif (Notopuro,1984). Demi memenuhi kebutuhan akan hasil pertanian maka tindakan atau suatu kegiatan pertanian perlu dilaksanakan melalui pengembangan usahatani.

Kecamatan Noemuti Timur merupakan salah satu Kecamatan yang berada di TTU yang juga berpotensi untuk usahatani padi sawah. Sehingga kita dapat mengetahui potensi usahatani padi sawah di Kabupaten Timor Tengah Utara antara lain: tahun 2013 dengan luas panen 469 ha, produksi 1.972 ton dan produktivitasnya $42,04 \mathrm{kw} / \mathrm{ha}$, tahun 2014 dengan luas panen 566 ha, produksi 2.136 ton dan produktivitasnya $37,74 \mathrm{kw} / \mathrm{ha}$ Sedangkan pada tahun 2015 dengan luas panen 798 ha, produksi 3.029 ton dan produktivitasnya sebesar $37,96 \mathrm{kw} / \mathrm{ha}$. (BPS Kecamatan Noemuti Timur, 2016).

Desa Haekto merupakan salah satu Desa yang berada di Kecamatan Noemuti Timur, Desa ini juga merupakan salah satu Desa yang berpotensi tinggi terhadap usahatani padi sawah. Data tiga tahun terakhir di BPS Kecamatan Noemuti Timur menunjukkan bahwa pada tahun 2013-2014 Desa haekto memiliki luas panen sebesar 250 ha, produksi 775 ton dan produktivitasnya $3,1 \mathrm{kw} / \mathrm{ha}$. Sedangkan pada tahun 2015 dengan luas panen yang sama yakni 250 ha tetapi produksinya meningkat menjadi 815 ton dan produktivitasnya 3,26 kw/ha. (Data Desa Haekto 2016).

Kegiatan usahatani padi sawah telah dilakukan sejak lama dan turun temurun oleh masyarakat Desa Haekto, yang mayoritas bekerja di usahatani padi sawah adalah tenaga kerja wanita karena kaum pria melakukan aktivitas lainnya seperti tukang kayu,tukang batu dan meramu hasil hutan. Keterlibatan kaum wanita pada usahatani padi sawah dapat menunjang ketahanan pangan pada tingkat keluarga yang berdampak pada ketahanan pangan yang lebih luas. Pada setiap tahap usahatani padi sawah selalu melibatkan kaum wanita seperti mengolah lahan, penanaman, pemupukan, panen dan pasca panen. Penelitian ini bertujuan untuk mengetahui gambaran umum dan faktor sosial ekonomi yang mempengaruhi curahan tenaga kerja wanita usahatani padi sawah di desa Haekto.

\section{Metode}

\section{A. Metode Pengambilan Sampel}

Penelitian ini telah dilaksanakan pada bulan januari - september $2018 \mathrm{~d}$

Desa Haekto Kecamatan Noemuti Timur Kabupaten Timor Tengah Utara.

Metode pengambilan sampel dalam penelitian ini sebagai berikut:

1. Populasi

Menurut (Sugiyono, 2008:115) Populasi adalah keseluruhan elemen atau unit penelitian yang memiliki karakteristik tertentu yang dijadikan sebagai objek penelitian. Populasi dari penelitian ini adalah seluruh petani padi sawah di Desa Haekto Kecamatan Noemuti Timur Kabupaten Timor Tengah Utara sebanyak 137 orang.

2. Sampel

Sampel adalah bagian kecil dari anggota populasi yang diambil menurut prosedur tertentu sehingga dapat mewakili populasinya, teknik pengambilan sampel dalam penelitian ini menggunakan teknik simple random sampling yaitu pengambilan sampel secara acak dimana setiap elemen dari populasi mempunyai peluang yang sama besar untuk terpilih ke dalam sampel.

Penetapan jumlah sampel penelitian dilakukan dengan cara menggunakan rumus slovin yaitu:

$$
n=\frac{\mathrm{N}}{1+\mathrm{Ne}^{2}}
$$

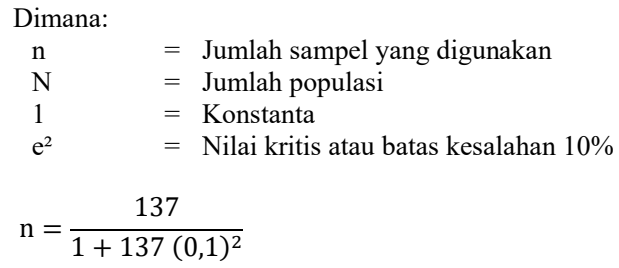

$\mathrm{n}=58$, jadi jumlah sampel yang digunakan adalah 58 responden.

\section{B. Metode Pengambilan Data}

Metode pengambilan data yang digunakan dalam penelitian ini adalah metode survey yang terdiri dari data primer dan sekunder. Data primer adalah data yang diperoleh melalui wawancara langsung dengan responden, sedangkan data sekunder adalah data yang diperoleh dari instansi terkait.

\section{Metode Analisis Data}

Untuk mengetahui faktor-faktor sosial ekonomi yang mempengaruhi curahan tenaga kerja wanita pada usahatani padi sawah di Desa Haekto Kecamatan Noemuti Timur Kabupaten Timor Tengah Utara menggunakan analisis linear berganda dengan menggunakan bantuan software SPSS version 16.0. Formulasinya sebagai berikut:

$\mathrm{Y}=A+b_{1} x_{1}+b_{2} x_{2}+b_{3} x_{3}+b_{4} x_{4}+b_{5} x_{5}+\mathrm{e} \ldots$

\section{Keterangan:}

$\mathrm{Y} \quad$ : Curahan tenaga kerja wanita pada usahatani padi sawah

$\mathrm{X}_{1}$ : Usia responden (tahun)

$\mathrm{X}_{2}$ : Luas lahan usahatani padi sawah (ha)

$\mathrm{X}_{3} \quad$ : Pendidikan responden (tahun)

$\mathrm{X}_{4}$ : Pengalaman responden (tahun)

$\mathrm{X}_{5} \quad$ : Jumlah tanggungan keluarga (orang) (Gujarati,2003)

\section{Hasil dan Pembahasan}

3.1. Gambaran Umum Usahatani Padi Sawah

A. Persiapan dan Pengolahan Lahan

B. Persemain dan penanaman

$$
>\text { Persemaian }
$$

$>$ Penanaman

C. Pemeliharaan

Setelah penanaman, tanaman padi perlu diperhatikan secara rutin.

Pemeliharaan yang dilakukan di lokasi penelitian yaitu:

$>$ Pengairan

$>$ Penyiangan

$>$ Pemupukan

$>\quad$ Pengendalian hama dan penyakit

D. Panen dan Pasca Panen

Panen adalah tahap akhir dalam bercocok tanam padi sawah panen dapat dilakukan apa bila padi sudah menguning demikian juga dengan daun dan malainya. Tangkai sudah kelihatan menunduk, dan gabah sudah berisi dan keras. Biasanya panen dilakukan oleh petani itu sendiri dan ada juga yang mengupakan kepada orang lain. Proses pemberian upah dihitung per are Rp 25.000 dengan cacatan bahwa padi hanya sebatas dipanen atau dipotong dan disimpan pada lahan tersebut atau diatas petak. Sedangkan proses 
pengangkutan diberi upah Rp 15.000 sehingga total biaya panen kepada tenaga kerja luar keluarga adalah $\mathrm{Rp} 40.000$. Kegiatan setelah panen adalah proses pasca panen sebagai berikut:

$$
\begin{array}{ll}
> & \text { Perontokan } \\
> & \text { Pengangkutan } \\
> & \text { Pembersihan } \\
> & \text { Pengeringan } \\
& \text { Penyimpanan }
\end{array}
$$

3.2. Analisis Data Dan Pengujian Hipotesis

\section{A. Hasil Perhitungan}

Untuk mengetahui faktor-faktor sosial ekonomi yang mempengaruhi curahan tenaga kerja wanita pada usahatani padi sawah di Desa Haekto Kecamatan Noemuti Timur Kabupaten Timor Tengah Utara menggunakan analisis linear berganda dengan menggunakan bantuan software SPSS version 16.0. Formulasinya sebagai berikut:

$Y=\beta_{0}+\beta_{1} X_{1}+\beta_{2} X_{2}+\beta_{3} X_{3}+\beta_{4} X_{4}+\beta_{5} X_{5}+$ ei

Berdasarkan hasil perhitungan memperoleh persamaan sebagai berikut:

$\mathrm{Y}=5.370+0.053 \mathrm{X}_{1}+0.529 \mathrm{X}_{2}+1.070 \mathrm{X}_{3}+0.028 \mathrm{X}_{4}+0.570 \mathrm{X}_{5}$

Tabel 1. Hasil Persamaan Faktor Curahan Jam Kerja Wanita Tani Desa Haekto

\begin{tabular}{lccc}
\hline Variabel & Koefisien & t-Statistic & Prob. \\
\hline C & 5.370 & 7.256 & 0.463 \\
X1(usia) & .053 & 0.110 & 0.631 \\
X2(Luas Lahan) & .529 & 0.058 & $0.000^{\mathrm{a}}$ \\
X3(Pendidikan) & -1.070 & 0.501 & $0.037^{\mathrm{b}}$ \\
X4(Pengalaman) & .028 & 0.154 & 0.857 \\
X5(Jumlah Tanggungan Keluarga) & .570 & 0.799 & 0.479 \\
R-squared & 0,659 & & \\
Prob(F-statistic) & $0,096^{\mathrm{c}}$ & & \\
\hline
\end{tabular}

Keterangan : a,b dan c signifikan pada $\alpha$ : 0,01, 0,05 dan 0,10

\section{B. Interpretasi Hasil Analisis Faktor Curahan Tenaga Kerja Wanita} Tani Desa Haekto

1. Pengaruh Usia Terhadap Curahan Jam Kerja Wanita Tani Desa Haekto

Usia mempunyai pengaruh yang positif dengan nilai 0,053 . Ini berarti jika usia meningkat 1 tahun menyebabkan curahan tenaga kerja wanita tani meningkat sebesar 0,053 orang. Hal ini sesuai dengan Wanda (2016) menyatakan usia berpengaruh positif terhadap curahan jam kerja wanita.

2. Pengaruh Luas Lahan Terhadap Faktor Curahan Jam Kerja Wanita Tani Desa Haekto

Luas lahan berpengaruh secara positif terhadap curahan jam kerja wanita tani dengan nilai 0,729. Ini menunjukkan bahwa jika luas lahan meningkat 1 ha menyebabkan curahan jam kerja meningkat sebesar 0,529 jam. Hal ini sesuai dengan Berliani (2017) menyatakan bahwa luas lahan berpengaruh positif dan signifikan terhadap curahan jam kerja wanita tani.

3. Pengaruh Pendidikan Terhadap Curahan Jam Kerja Wanita Tani Desa Haekto

Pendidikan mempunyai pengaruh secara negatif dengan produksi jagung Desa Lorotulus dengan nilai 1,070. Angka tersebut memiliki arti jika pendidikan meningkat 1 tahun maka terjadi penurunan jam kerja sebesar 1,070 jam. Hal ini sesuai dengan Berliani (2017) menyatakan bahwa pendidikan berpengaruh negatif terhadap curahan jam kerja wanita tani.

4. Pengaruh Pengalaman Berusahatani Terhadap Curahan Jam Kerja Wanita Tani Desa Haekto.

Pengalaman berusahatani berpengaruh positif terhadap curahan jam kerja wanita tani Desa Haekto dengan nilai 0.28 . Hal ini menunjukkan jika pengalaman meningkat 1 tahun maka curahan jam kerja meningkat 0,28 jam.

5. Pengaruh Jumlah Tanggungan Keluarga Terhadap Curahan Jam Kerja Wanita Tani Desa Haekto

Jumlah tanggungan keluarga mempunyai pengaruh positif terhadap curahan jam kerja wanita tani Desa Haekto dengan nilai 0,570 . Ini berarti jika tanggungan keluarga meningkat sebesar 1 orang maka curahan jam kerja wanita tani meningkat sebesar 0.570 jam.

\section{Koefisien Determinasi}

Koefisien determinasi ialah variabel terikat (Y) yang mampu dijelaskan oleh seluruh variabel bebas (X) dalam model nilai koefisien determinasi merupakan perbandingan antara jumlah kuadrat regresi dengan kuadrat total. Dari Tabel 1. dikatakan bahwa variabel usia, luas lahan, lama pendidikan, pengalaman, dan jumlah tanggungan keluarga memiliki pengaruh sebesar $65,9 \%$ terhadap curahan jam kerja wanita tani Desa Haekto, sisanya sebesar $34,1 \%$ dipengaruhi oleh faktor lain yang tidak diteliti dalam penelitian ini.

\section{Uji Simultan atau Secara Serempak}

Uji $\mathrm{F}$ adalah untuk mengetahui apakah variabel bebas dalam model persamaan faktor curahan jam kerja wanita tani padi sawah Desa Haekto memiliki pengaruh secara bersama-sama terhadap variabel terikat. Variabel bebas yaitu usia, luas lahan, lama pendidikan, pengalaman usahatani, dan jumlah tanggungan keluarga. Pada Tabel 1 dapat dilihat dari probabilitas $\mathrm{F}$ hitung 0,096 , variabel bebas berpengaruh nyata terhadap variabel terikat dengan $\alpha=10 \%$.

\section{Simpulan}

Gambaran usahatani padi sawah diawali dengan (1) persiapan lahan dan pengolahan lahan. (2) persemaian (3) penanaman. (4) pengairan. (5) penyiangan. (6) pengendalian hama dan penyakit. (7) Pemupukan. (8) Panen. (9) Pasca Panen dilakukan dengan beberapa cara yaitu: perontokan, pengangkutan, pembersihan, pengeringan, dan penyimpanan. Faktor yang mempengaruhi curahan jam kerja wanita tani padi sawah Desa Haekto secara signifikan adalah luas lahan dan lama pendidikan. Usia, pengalaman, dan jumlah tanggungan keluarga memiliki pengaruh yang positif.

\section{Daftar Pustaka}

Berliani, R. (2017). Pengaruh Faktor-Faktor Sosial Terhadap Curahan Waktu Kerja Kelompok Wanita Tani Padi di Desa Banjaran Kecamatan Bangsri Kabupaten Jepara.Program Studi S1 Agribisnis. Universitas Diponegoro. Semarang.

Badan Pusat Statistik. 2013. Kabupaten Timor Tengah Utara Dalam Angka.Badan Pusat Statistik. Kabupaten Timor Tengah Utara

Badan Pusat Statistik. 2014. Kabupaten Timor Tengah Utara Dalam Angka. Badan Pusat Statistik. Kabupaten Timor Tengah Utara

Badan Pusat Statistik. 2015. Kabupaten Timor Tengah Utara Dalam Angka Badan Pusat Statistik. Kabupaten Timor Tengah Utara

Gujarati N. Damodar. 2003. Basic Econometric, Fourt Edition. New York: McGraw-Hill

Notopuro H. 1984. Peranan Wanita dalam pembangunan di Indonesia: Edisi Revisi.Jakarta: Balai Aksara.

Sugiyono. 2008. Metode Penelitian Kuantitatif Kualitatif dan R\&d. Bandung Alfabeta.

Wanda, O. C. G. (2016). Analisis faktor-faktor yang mempengaruhi curahan waktu kerja wanita di Desa Banjaragung Kabupaten Jombang pada industri sepatu sebagai bentuk kontribusi terhadap ekonomi keluarga. Jurnal Ilmiah Mahasiswa FEB, 4(1). 